\title{
Telomere Maintenance Gene
}

National Cancer Institute

\section{Source}

National Cancer Institute. Telomere Maintenance Gene. NCI Thesaurus. Code C20338.

Telomere Maintenance Genes encode specialized proteins bound to telomeric DNA repeats and directly involved in maintaining/protecting chromosome telomere ends to prevent a damage response that halts cell proliferation. Telomerase, which lengthens telomeric DNA by RNA-templated addition of repeated DNA sequences, is regulated by proteins that bind to the telomeric DNA repeats and to additional proteins to assemble a higher-order telomeric complex. $(\mathrm{NCl})$ 